\title{
MASSIVE CLOZAPINE OVERDOSE: WHAT TO EXPECT?
}

\author{
Viktorija Erdeljić Turk ${ }^{1}$, Marta Kučan ${ }^{2}$ \& Dinko Vitezić $\dot{c}^{3,4}$ \\ ${ }^{I}$ Division of Clinical Pharmacology, Department of Medicine, University Hospital Zagreb, Zagreb, Croatia \\ ${ }^{2}$ Community Health Centre of Primorje-Gorski Kotar County, Rijeka, Croatia \\ ${ }^{3}$ University of Rijeka Medical School, Rijeka, Croatia \\ ${ }^{4}$ University Hospital Centre Rijeka, Rijeka, Croatia
}

received: 22.9.2020;

revised: 30.10.2020;

accepted: 5.11.2020

$* * * * *$

\section{INTRODUCTION}

Clozapine is an atypical antipsychotic drug indicated for treatment-resistant schizophrenia. Despite its superior clinical efficacy, many deleterious adverse events, including agranulocytosis, have resulted in its more judicious use (Asenjo Lobos et al. 2010).

The most frequently reported symptoms of clozapine intoxication are impaired alertness and tachycardia; other symptoms include: hyperthermia, alterations in consciousness, dysarthria, ataxia, seizures, cardiac arrhythmias, excessive bronchial mucus, hypersalivation, miosis, blood dyscrasias, pancreatitis and hepatitis (Le Blaye et al. 1992, Krämer et al. 2010). Studies that evaluated the case fatality rate with various antipsychotics concluded that clozapine was far more toxic than other antipsychotics (Ferrey 2018).

To the best of our knowledge, this is the fist case report describing treatment and outcomes following a massive overdose of clozapine, amounting to 46.7 times the recommended patient's daily dose of clozapine.

\section{CASE REPORT}

We report on a 55-year old male with history of shizoafective disorder who was discovered by his wife 30 minutes after ingestion of 7,000 $\mathrm{mg}$ of clozapine (70 tablets of $100 \mathrm{mg}$ ) in a suicide attempt. That was his first suicide attempt triggered by his mother's death. He was on long-term treatment with clozapine $150 \mathrm{mg} /$ day, haloperidol $5 \mathrm{mg}$ /day, levopromazine $75 \mathrm{mg}$ /day, biperiden $4 \mathrm{mg} /$ day, and valproate $1200 \mathrm{mg} /$ day for his psychiatric conditions, and on methotrexate $12.5 \mathrm{mg} / \mathrm{week}$ and folic acid $5 \mathrm{mg} /$ week for rheumatoid arthritis. He also had chronic obstructive pulmonary disease (COPD) but received no specific COPD treatment. His past medical history was negative for cardiac dysrithmia or hypertensive heart disease.

He was admitted to the Emergency Room (ER) within an hour of intoxication with acute onset of confusion, somnolence with intermittent periods of agitation, meaningless talk, facial grimacing and choreatic movements. He was treated immediately with gastric lavage, activated charcoal and intravenous fluids. His body temperature was $36.7^{\circ} \mathrm{C}$, blood pressure
$124 / 77 \mathrm{mmHg}$, pulse rate $136 / \mathrm{min}$., respiratory rate $16 /$ min., $\mathrm{SaO}_{2} 96 \%$. Arterial blood gas analysis was normal. Electrocardiogram showed sinus tachycardia without QTc prolongation. His Glasgow Coma Score was 12. His pupils were isocoric and reactive to light. The remainder of the psychical examination was unremarkable. Blood tests showed leukocytosis $\left(14.3 \times 10^{9} / \mathrm{L}\right)$ and increased serum C-reactive protein levels $(34.6 \mathrm{mg} / \mathrm{L})$. Liver tests, creatinine, BUN, $\mathrm{CK}, \mathrm{LDH}$, potassium, sodium and calcium levels were within normal range. Urine analysis was normal. Due to his stable vital signs and rapid detoxification after overdose, clozapine serum levels were not measured. On chest X-rays no signs of pneumonia were noted. No rigidity or tremor were found. After a psychiatrist consultation, he was closely monitored in the ER during 24 hours. Antipsychotics were stopped and only diazepam in addition to psychical restraint, if needed, were recommended. During this time, no worsening in his psychical status was observed and his vital signs remained stable. On his 24 hour follow up, blood tests still showed leucocytosis $\left(19.0 \times 10^{9}\right)$ and increased serum C-reactive protein levels $(45.0 \mathrm{mg} / \mathrm{L})$, and an increase in $\mathrm{CK}$ level was noted (from $67 \mathrm{U} / \mathrm{L}$ to $460 \mathrm{U} / \mathrm{L}$ ). He was discharged to a psychiatric hospital with recommendations for close observation, follow up, and antibiotic treatment with amoxicillin/clavulanic acid was started.

After two days the patient was readmitted to the ER due to fever and worsening of his general condition. His body temperature was $38.0^{\circ} \mathrm{C}$, blood pressure $110 / 70$ $\mathrm{mmHg}$, pulse rate $121 / \mathrm{min}$., respiratory rate $20 / \mathrm{min}$, $\mathrm{SaO}_{2} 91 \%$. Electrocardiogram showed sinus tachycardia without QTc prolongation. His Glasgow Coma Score was 11. Blood tests showed leucocytosis $\left(16.5 \times 10^{9}\right)$, increased serum C-reactive protein $(171 \mathrm{mg} / \mathrm{L})$, creatine kinase $(707 \mathrm{U} / \mathrm{L})$, fibrinogen $(7.0 \mathrm{~g} / \mathrm{L})$ and procalcitonin $(0.675 \mathrm{ug} / \mathrm{L}) \mathrm{levels}$. Liver and thyroid function tests, creatinine, BUN, LDH, potassium, sodium and calcium levels, activated partial thromboplastin time and international normalized ratio were within normal range. Urine and blood cultures were negative. On psychical examination, he was confused, agitated, and seen to be coughing with sputum production. On neurological examination, pupils were isocoric and reactive and he had no localizing deficits. No rigidity or tremor were 
found. Right-sided pneumonia was observed on chest $\mathrm{X}$-ray. Computed tomography CT scan of his brain showed no acute infarct or haemorrhage. He was admitted to the intensive care unit (ICU) with an initial diagnosis of aspiration pneumonia, and treated initially with ceftriaxone and clindamycin. These antibiotics were subsequently changed to cefepime after Pseudomonas aeruginosa was isolated in his tracheal aspirate. The supportive treatment started at the ER was continued with intravenous fluids, ranitidine and thromboprophylaxis was performed with enoxaparin. Creatine kinase levels returned to normal on the forth day of admission to the ICU $(108 \mathrm{U} / \mathrm{L})$. His temperature, leucocytes and CRP, fibrinogen and procalcitonin levels returned to normal on the $7^{\text {th }}$ day of admission. His vital signs remained stable. Confusion disappeared, his comprehension and speech improved, and his attention normalized gradually. Due to his good clinical recovery, the follow-up chest X-ray was not performed. After 13 days in the ICU he was discharged in good physical condition to a psychiatric hospital. Psychotropic medications were ceased at first but subsequently antipsychotic treatment with promazine, clonazepam, diazepam and valproate was reintroduced. Clozapine was not restarted. In follow up, he remained stable without relapse for about 6 months. No further suicidal ideations or attempts have been reported.

\section{DISCUSSION}

This is a case of massive clozapine overdose in a suicide attempt. We performed an extensive literature search, and to the best of our knowledge this is the first report describing treatment and outcome of an intoxication with a clozapine dose which is 46.7 times higher that the patient's recommended daily dose $(7,000 \mathrm{mg}$ vs. $150 \mathrm{mg}$ ).

The reported mortality rate in case of clozapine intoxication in Western countries is $12 \%$ (Summary of Product Characteristics - Clozaril (clozapine). Mylan Products Ltd.). Based on the toxokinetics of clozapine, there seems to be a high interindividual variability, and severe clozapine intoxications can already occur after ingestion of doses in the low therapeutic range, especially in patients who were previously not exposed to clozapine. (Pollak \& Shafer 2004, West et al. 2013). The fatal dose of clozapine is not clearly established but several published reports suggest that most clozapine overdose fatalities occur at doses greater than 2,000 $\mathrm{mg}$ and are primarily associated with cardiac failure or aspiration pneumonia (Renwick et al. 2000, Ciappini et al. 2020).

Since there is no specific antidote for clozapine, the recommended approach includes gastric lavage and administration of activated charcoal within the first 6 hours after the ingestion of a substantial amount of the medication, symptomatic therapy and monitoring. This approach allows for a successful outcome even a with high-dose intoxication (Le Blaye et al. 1992, Piccini et al. 1997, Broich et al. 1998, Reddy et al. 2013).

Favourable outcomes following intoxications with doses in excess of 10,000 $\mathrm{mg}$ have been reported earlier, however, only in patients on a substantially higher recommended daily dose of clozapine taken during a long-term treatment (300-400 mg/day) and even than, the overdose amounted to 30 times the patients daily dose of clozapine, which is significantly lower as compared to our case (Piccini et al 1997, Sartorius et al. 2002, He et al. 2007). Furthermore, such high-dose toxicity related data are mostly available through articles with aggregated data that report the doses as ranges, making it impossible to determine the effects in a specific patient (Le Blaye et al. 1992, Reith et al. 1998, Capel et al. 2000).

\section{CONCLUSION}

This case confirms that signs and symptoms after clozapine intoxication are variable and that a massive intoxication may not be lethal in every case with timely detoxification, supportive measures and close monitoring for early and late onset of complications.

\section{Acknowledgements: None.}

\section{Conflict of interest: None to declare.}

\section{Contribution of individual authors:}

Viktorija Erdeljić Turk \& Dinko Vitezić: manuscript writing, literature search, interpretation of data.

Marta Kučan: literature search, interpretation of data.

\section{References}

1. Asenjo Lobos C, Komossa K, Rummel-Kluge C, Hunger H, Schmid F, Schwarz $S$ et al.: Clozapine versus other atypical antipsychotics for schizophrenia. Cochrane Database Syst Rev 2010; 10:CD006633. doi:10.1002/14651858.CD006633.pub2

2. Broich K, Heinrich $S$ \& Marneros A: Acute Clozapine Overdose: Plasma Concentration and Outcome. Pharmacopsychiatry 1998; 31:149-51

3. Capel MM, Colbridge MG \& Henry JA: Overdose profiles of new antipsychotic agents. Int $J$ Neuropsychopharmacol 2000; 3:51-4

4. Ciappini S, Schifano F, Corkery JM \& Guirguis A: Focus on Clozapine Withdrawal- and Misuse-Related Cases as Reported to the European Medicines Agency (EMA) Pharmacovigilance Database. Brain Sci 2020; 10:105

5. Ferrey AE, Geulayov G, Casey D, Wells C, Fuller A, Bankhead $C$ et al.: Relative toxicity of mood stabilisers and antipsychotics: case fatality and fatal toxicity associated with self-poisoning. BMC Psychiatry 2018; 18:399

6. He JL, Xiang YT, Li WB, Cai ZJ \& Ungvari GS: Hemoperfusion in the treatment of acute clozapine intoxication in China. J Clin Psychopharmacol 2007; 27:667-7 
7. Krämer I, Rauber-Lüthy C, Kupferschmidt H, Krähenbühl $S$, \& Ceschi A: Minimal dose for severe poisoning and influencing factors in acute human clozapine intoxication: a 13-year retrospective study. Clin Neuropharmacol 2010; $33: 230-4$

8. Le Blaye I, Donatini B \& Hall M: Acute over dosage with clozapine: A review of the available clinical experience. Pharm Med 1992; 6:169-78

9. Piccini $G$, Ceroni P, Marchesi $C$, Maggini $C \&$ Maestri $G$ : Acute clozapine overdosage. Br J Psychiatry 1997; 170:290

10. Pollak PT \& Shafer SL: Teaching Application of Clinical Pharmacology Skills Using Unusual Observations from Clozapine Overdoses. The Journal of Clinical Pharmacology 2004; 44:141-9

11. Reddy SM, Khairkar PH \& Jajoo U: 70 Hours of Coma by Clozapine Intoxication. The Journal of Neuropsychiatry and Clinical Neurosciences 2013; 25:22-3
12. Reith D, Monteleone JP, Whyte IM, Ebelling W, Holford $N H \&$ Carter GL: Features and toxicokinetics of clozapine in overdose. Ther Drug Monit 1998; 20:92-7

13. Renwick AC, Renwick AG, Flanagan RJ, and Ferner RE: Monitoring of clozapine and norclozapine plasma concentration-time curves in acute overdose. J Toxicol Clin Toxicol 2000; 38:325-8

14. Sartorius A, Hewer W, Zink M \& Henn F: High-Dose Clozapine Intoxication. J Clin Psychopharmacol 2002; 22:91-2

15. Summary of Product Characteristics - Clozaril (clozapine). Mylan Products Ltd. Accessed via https://www.medicines.org.uk/emc/product/4411/smpc\#gr ef on 24/10/20 [date of revision of the text April 2020]

16. West S, Jeffery-Smith A, Brownlee $W$ \& Kenedi $C$ : Covert clozapine overdose: Clozapine toxicity in a naive patient. Aust N Z J Psychiatry 2013; 47:120

Correspondence:

Viktorija Erdeljić Turk, MD

Division of Clinical Pharmacology, Department of Medicine, University Hospital Zagreb

Kišpatićeva 12, 10000 Zagreb, Croatia

E-mail:verdeljic@gmail.com 